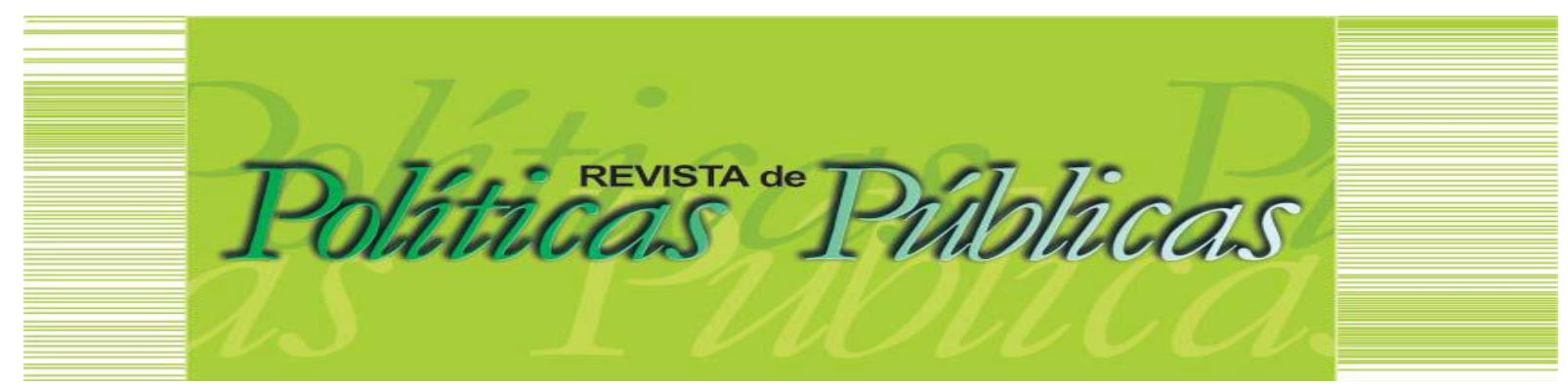

\title{
REMOÇÕES E MEGAEVENTOS NO RIO DE JANEIRO: a luta de resistência dos moradores da Vila Autódromo ${ }^{1}$
}

Rafael Soares Gonçalves ${ }^{1}$ Josiane do Vale ${ }^{2}$

\section{Resumo:}

Desde a sua escolha como sede dos Jogos Olímpicos de 2016, a cidade do Rio de Janeiro passou por uma grande transformação urbana com a construção de instalações esportivas, recuperação de áreas consideradas degradadas e investimentos no setor de transportes. Muitas favelas localizadas em áreas com grande valorização imobiliária foram total ou parcialmente destruídas sob o pretexto da preparação da cidade. 0 presente trabalho tem como objetivo fazer uma análise sobre esse período de preparação da cidade para a realização dos Jogos Olímpicos e os impactos sociais resultantes desse processo, especialmente no caso da favela da Vila Autódromo, localizada nas proximidades do Parque Olímpico, lugar onde se concentrou a maior parte dos equipamentos esportivos para a realização das competições.

Palavras-chave: Jogos Olímpicos. Remoção de favelas. Rio de Janeiro. Vila Autódromo.

EVICTIONS AND MEGAEVENTS IN RIO DE JANEIRO: the resistance struggle of the inhabitants of Vila Autódromo

\section{Abstract:}

The city of Rio de Janeiro has gone through major urban transformation with the construction of sports facilities, recovery of areas considered degraded and investments in the transportation sector since it was chosen for the 2016 Olympic Games. Many slums located in areas with great real estate valorization were total or partially destroyed under the pretext of the preparation of the city. This paper aims to analyze the period of preparation of the city for the Olympic Games and the social impacts resulting from this process, especially in the case of the slum Autódromo Village, located near the Olympic Park, where it concentrated the majority of the sports equipment to carry out the competitions.

Keywords: Olympic Games. Favela evictions. Rio de Janeiro. Vila Autódromo.

Recebido em: 29/08/2018. Aprovado em: 28/03/2019 DOI: http://dx.doi.org/10.18764/2178-2865.v23n1p441-455

\footnotetext{
${ }^{1}$ Advogado e historiador. Doutor em História pela Universidade de Paris VII. Professor do departamento de Serviço Social da Pontifícia Universidade Católica do Rio de Janeiro (PUC-RJ). Coordenador do Laboratório de Estudos Urbanos e Socioambientais (LEUS), Jovem Cientista do Nosso Estado pela FAPERJ e pesquisador de produtividade do CNPQ. Endereço: R. Marquês de São Vicente, 225 - Gávea, Rio de Janeiro - RJ. CEP: 22451-900. E-mail: rafaelsgoncalves@yahoo.com.br

2 Mestre pelo Programa de Pós-Graduação do Departamento de Serviço Social da PUC-RJ. E-mail: vale.josiane@yahoo.com
} 


\section{INTRODUÇÃO}

A cidade do Rio de Janeiro é certamente um dos casos mais emblemáticos dos impactos dos grandes eventos internacionais para o planejamento urbano. Provavelmente, pela primeira vez na história, uma cidade sediou quase todos os eventos internacionais de grande visibilidade mundial. Essa dinâmica se iniciou, de maneira mais distante, com a conferência da ONU sobre o Meio Ambiente de 1992. Depois de ter tentado, sem sucesso, sediar os jogos Olímpicos de 2000 e de 2008, a candidatura da cidade do Rio de Janeiro para os Jogos Pan-americanos de 2007 foi aceita e se configurou como um divisor de águas. A partir dessa data, como foi analisado por Gonçalves (2013), a cidade recebeu todas as candidaturas que concorreu, tendo organizado os Jogos Militares de 2011, a última conferência da ONU sobre o Meio Ambiente (Rio+20), a Copa das Confederações de futebol de 2013, as Jornadas Mundiais da Juventude com o Papa, também em 2013, assim como a Copa do Mundo de 2014 e os Jogos Olímpicos de 2016.

Os resultados obtidos pela cidade após dez anos ininterruptos de organização e realização de grandes eventos não são nada animadores. O Estado do Rio de Janeiro está completamente falido, devendo fornecedores, com investimentos parados e salários e pensões atrasadas. Da mesma forma, a prefeitura anuncia cortes no orçamento para adequá-lo à nova realidade pós-jogos olímpicos. Os gastos exorbitantes vieram com acusações de uma corrupção em toda a máquina pública, o que levou à prisão do ex-governador Sergio Cabral e toda a cúpula do seu governo. As investigações estão chegando também na máquina municipal. A violência retomou os índices de uma década atrás, fazendo com que a cidade tenha recebido tropas federais no final de julho de 2017 e o Estado esteja sob intervenção federal desde fevereiro de 2018. O horizonte nebuloso que se desenha é bem distante da euforia que tomava a cidade e o país quando dos anúncios sucessivos da cidade como cidade-sede dos eventos supracitados.

Ora, a conquista desses eventos modificou completamente a forma de planejar e gerir a cidade, mobilizando importantes recursos públicos e atraindo vultosos investimentos privados. Observou-se, segundo Gonçalves (2014), uma importante retomada econômica, que parecia vencer o auspício do esvaziamento econômico e do aumento exponencial da violência. As Unidades de Polícia Pacificadora (UPPs) reduziram os conflitos armados nas favelas, trazendo uma suposta sensação de segurança para a população, mesmo que às custas da violação dos direitos humanos dos moradores de favelas, já que o modus operandi violento da polícia não foi alterado. 0 Rio de Janeiro retomou parte da sua centralidade econômica e política que perdera nas últimas décadas e voltava a esbanjar a sua vocação de capital, sendo mais do que nunca a vitrine internacional do país. 
Tais eventos internacionais permitem a mobilização de recursos e a construção de discursos voltados para o ressurgimento das cidades e para a construção de novas identidades locais. Apesar da efemeridade desses eventos, de acordo com Gonçalves (2014), eles deixam marcas importantes nas cidades que os sediam e asseguram a legitimidade necessária para importantes intervenções urbanas. A concepção de cidade a partir da organização de grandes eventos legitima políticas de empreendedorismo urbano, projetos vultosos de renovação urbana e reitera a visão do espaço urbano como se este fosse vazio de memórias e significados. A pretensa importância dos eventos para o futuro da cidade e o curto tempo para prepará-la acabaram justificando todo tipo de negociata e impondo um modelo consensual de cidade sem o debate necessário.

Gonçalves (2014) descreve que o espetáculo se apresenta, a partir da reflexão de Guy Debord (1967), como um instrumento de unificação. É preciso compreender que tais eventos são grandes espetáculos internacionais com forte cunho midiático para as cidades que os recebem. Pensar a cidade como espetáculo implica a valorização da imagem da cidade a partir de modelos internacionalmente aceitos: a cidade torna-se uma espécie de produto a ser anunciada e comercializada. Observa-se, assim, a construção de uma espécie de imagem espacial que seria, segundo Lussault (2007), a relação entre uma aparente visibilidade e um conjunto de significações. No caso carioca, essa nova economia semiótica urbana é excludente, consolidando espaços elitistas e pasteurizados sem respeito à diversidade urbana e à experiência do cotidiano da população. (GONÇALVES, 2014).

O caso do modelo difundido ao mundo pela cidade de Barcelona é emblemático no que diz respeito à produção de consensos. Conforme sustenta um dos seus críticos mais vigorosos, o antropólogo Manuel Delgado (2007), o projeto desenhado para Barcelona é antes de mais nada um projeto de mercado. Trata-se de um autêntico paradigma de marketing urbano, uma estratégia de promoção, difusão e comercialização, cujo objeto é a própria cidade. Para evitar conflitos diante do aumento dos custos para morar em uma cidade sede de grandes eventos, essa mercadoria requer, segundo Manuel Delgado (2007), de uma adequada combinação de teorização das aparências e de um vocabulário devidamente marcado por invocações e valores abstratos do pensamento politicamente correto.

Assim como o Rio de Janeiro atual, Barcelona é o exemplo de uma aliança generalizada entre promotores imobiliários e gestores públicos. Esse modelo se estabeleceu a partir de alterações legislativas para o aumento generalizado dos padrões de edificabilidade, do uso recorrente das forças policiais para medidas de controle urbano, de intervenções de renovação urbana e requalificação de zonas consideradas abandonadas e degradadas e, por fim, da mercantilização excessiva do solo. As intervenções urbanas, conforme sustenta Manuel Delgado (2007), suscitam um efeito dominó do 
processo de renovação urbana, permitindo o avanço exponencial da especulação imobiliária. Enfim, processo muito similar com o que se observa atualmente no Rio de Janeiro. No caso carioca, é preciso acrescentar a retomada das remoções de favelas, sobretudo em áreas de grande interesse imobiliário. Segundo dados do Comitê de acompanhamento da Copa e das Olimpíadas (2015), foram removidas na cidade do Rio de Janeiro entre 2008 e 2015, em torno de 22.059 famílias, sejam por questões de pretenso risco do local de moradia ou por exigências das obras de preparação da cidade. Um dos casos mais emblemáticos foi o da Vila Autódromo tanto pela resistência dos seus moradores quanto, como veremos a seguir, pela insistência da prefeitura em retirar os moradores dali.

\section{A ELITIZAÇÃO DO ESPAÇO URBANO: o Projeto Parque Olímpico e a Vila Autódromo}

A noção de cidade-espetáculo implica a reorganização de uma nova visibilidade urbana que permita atrair capitais internacionais. Para tanto, é preciso forjar uma nova visão de cidadania. $A$ participação popular é valorizada no discurso, mas descaracterizada na prática. O espetáculo, segundo Gonçalves (2014), enquadra a participação e sugere um consenso, mesmo que a dinâmica de organização do espetáculo promova medidas contrárias à população e viole direitos, sobretudo dos mais pobres. Existe um forte agenciamento das forças locais através de parcerias público-privadas; da valorização do empreendedorismo urbano; das pretensas melhoras da qualidade de vida com novos investimentos em equipamentos urbanos; da construção de um patriotismo local, e, eventualmente, de uma maior oferta de trabalho por certo período.

Se o espetáculo pauta a angariação de recursos e a mobilização da população, 0 planejamento urbano é condicionado por modelos urbanos internacionalmente aceitos, como citamos do padrão Barcelona. O espaço urbano passa a ser pensado somente como forma, como agrupamento de objetos e não como forma-conteúdo, como sistema de objetos e ações. As novas imagens difundidas da cidade se prontificam a construir novas práticas sociais, suscitando um conjunto de valores, sintetizando novas formas de ser e de viver no espaço urbano. Tal processo implica uma simplificação da imagem da cidade que reflete os interesses e modelos das classes dominantes, e procura reconstruir a identidade urbana através da omissão de grupos, práticas e espaços da cidade.

Os grandes eventos internacionais são a justificativa concreta para se empreender grandes renovações urbanas e apresentam uma forte ideologia que procura consolidar consensos no entorno da imagem do ressurgimento urbano. Esses discursos mascaram, no entanto, as consequências concretas das intervenções urbanas, invisibilizando ganhadores e perdedores no decurso do processo. Segundo Smith (2006), a linguagem coerente do renascimento urbano é a prova da generalização da gentrificação na paisagem urbana. A própria noção de revitalização ou de renovação, como analisa Sanchez (2009), sugere que o gestor/planejador seria criador da vida social, 
sublinhando que as características pretéritas locais não estariam de acordo com os conteúdos desejáveis para o novo projeto de cidade.

A Vila Autódromo foi uma das várias favelas que sofreram o processo de remoção e seu caso obteve grande repercussão pela mobilização de seus moradores. A favela se localiza em área limítrofe entre os bairros de Jacarepaguá e Barra da Tijuca, área de forte interesse do mercado imobiliário pela possibilidade de expansão e valorização imobiliária. O bairro da Barra da Tijuca é conhecido pela presença de grandes condomínios em que, alguns, possuem em seu interior lojas, academias, áreas de lazer, entre outros serviços, destinados à classe média alta, assim como a presença de centros comerciais e mesmo escolas. O bairro da Barra da Tijuca é conhecido pela presença de grandes condomínios em que, alguns, possuem em seu interior lojas, academias, áreas de lazer, entre outros serviços, destinados à classe média alta, assim como a presença de centros comerciais e mesmo escolas. A Barra da Tijuca surge como uma extensão da Zona Sul, área nobre da cidade, já que grande parte do solo dessa região já estava esgotado. De acordo com Gaffney (2013), entre 2007 e 2010, grande parte dos projetos imobiliários da cidade do Rio de Janeiro foram destinados para a Barra da Tijuca, o que demonstra a importância do bairro para o mercado imobiliário. A ausência de políticas habitacionais, o deficiente sistema de transporte e a grande oferta de empregos nos condomínios e shopping centers acarretaram no crescimento das favelas da região. Por conta da sua localização, a Vila Autódromo sofreu diversas tentativas de remoção, que se concretizou finalmente às vésperas da abertura dos Jogos Olímpicos.

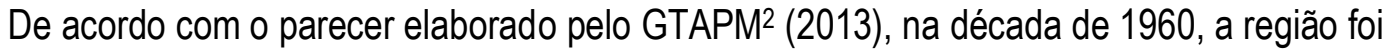
escolhida para que fosse construído o Autódromo de Jacarepaguá, mas como ficava próxima a uma lagoa, a área precisou ser aterrada. Com o aterramento ao redor da lagoa, pescadores se instalaram na década de 1970, dando início à formação da Vila Autódromo. 0 crescimento da favela acompanhou o desenvolvimento dos bairros adjacentes. No final da década de 1980, foi criada a Associação dos Moradores, Pescadores e Amigos da Vila Autódromo (AMPAVA), que tinha como objetivo defender os interesses da favela, como por exemplo, o acesso a serviços básicos como água, energia elétrica, documentação, entre outros. Ainda no final dessa década, a prefeitura reassentou famílias retiradas de outra favela próxima da Vila Autódromo, aumentando o número de moradores no local.

Segundo o GTAPM (2013), sendo as terras pertencentes ao Governo do Estado, o mesmo conferiu aos moradores o título de Concessão de Direito Real de Uso ${ }^{3}$ (CDRU) durante a década de 1990, gravando, em 2005, a área como de Especial Interesse Social4. Apesar de respaldados juridicamente, os moradores da Vila Autódromo começaram a sofrer com a ameaça de remoção desde a década de 1990. Em 1993, o então subprefeito de Jacarepaguá e da Barra da Tijuca, Eduardo Paes (que se tornou prefeito entre 2009 e 2016, e um dos responsáveis pela realização dos 
Jogos Olímpicos na cidade) moveu uma Ação Civil Pública, que defendia a remoção da favela por considerar que esta causava danos urbano, estético e ambiental. Em 1996, a cidade do Rio de Janeiro foi atingida por chuvas intensas, o que resultou em mortos e em grande número de desabrigados. Esse contexto trouxe novamente à discussão a necessidade de remoção de favelas, inclusive da Vila Autódromo, por serem consideradas como uma pretensa área de risco.

Essa área foi por muitos anos o autódromo da cidade do Rio de Janeiro e, apesar da perspectiva de valorização imobiliária da área, a Vila Autódromo era um dos poucos núcleos habitados. Observava-se, ali, um estoque importante de terras para a possibilidade de lançamentos imobiliários futuros. A perspectiva de utilização do Autódromo como nova fronteira imobiliária já se desenhara com a escolha, em 2002, do Rio de Janeiro como sede da edição dos $15^{\circ}$ Jogos Pan-americanos, fazendo com que a favela fosse alvo novamente do discurso de remoção, sobretudo pelo fato que parte dos equipamentos para os Jogos Pan-americanos foram instalados no Autódromo de Jacarepaguá em uma estratégia da prefeitura para fazer dessa área o principal setor dos Jogos Olímpicos.

Paralelamente ao processo de remoção, diversas obras estavam em andamento nas proximidades da Vila Autódromo. Foi construído um corredor expresso de ônibus, o chamado BRT (Bus Rapid Transit), ligando as instalações olímpicas da Barra da Tijuca com outras instalações no bairro de Deodoro. Ao lado da favela, foi construído o Parque Olímpico e dois prédios que foram usados como centro de mídia durante a realização dos Jogos Olímpicos e que, posteriormente, se tornou um prédio comercial. Segundo Guimarães (2015), o Consórcio Rio Mais, formado pelas empreiteiras Odebrecht, Andrade Gutierrez e Carvalho Hosken, foi o responsável pela construção das instalações esportivas e do alojamento para os atletas. Após os Jogos, o Consórcio recebeu da prefeitura uma área de aproximadamente $1.180 .000 \mathrm{~m}^{2}$ para a construção de edifícios residenciais, centros comerciais e hotéis. Trata-se de uma área pública que a prefeitura repassou para a inciativa privada, através de uma parceria público-privada, e que engloba também a área ocupada pela Vila Autódromo.

\section{A LUTA CONTRA A REMOÇÃO DA VILA AUTÓDROMO}

A realização dos Jogos Olímpicos de 2016 possibilitou que o poder público realizasse a remoção de inúmeras famílias da Vila Autódromo. Segundo dados da prefeitura, das quase 800 famílias residentes no local, apenas 20 permaneceram. (RIO DE JANIERO, 2016). Mesmo o projeto vencedor para o parque olímpico no local prevendo a permanência da favela e a sua urbanização, a prefeitura apresentou diversas justificativas para a remoção da Vila Autódromo, como a necessidade de um perímetro de segurança para os equipamentos dos jogos olímpicos, a necessidade de 
alargamento de vias próximas e mesmo a alegação de risco ambiental pela proximidade das casas com a Lagoa de Jacarepaguá.

Segundo Brum (2013), o então prefeito, Eduardo Paes, alegou que a Vila Autódromo ocupava uma área próxima de proteção ambiental e que, por essa razão, o título de posse concedido anteriormente não seria válido. Apesar dessa alegação, a realização de obras pela prefeitura para os Jogos Olímpicos desmatou áreas que deveriam ser protegidas por leis ambientais, como foi o caso da construção do Campo de Golfe e do corredor viário Transolímpica; só este último previa a destruição de 200 mil m$^{2}$ de Mata Atlântica5 ${ }^{5}$ Gonçalves e França (2010) afirmam que o discurso ambiental é apropriado de forma diferente pelos poderes públicos e a sociedade em geral, quando o foco é a favela ou empreendimentos de maior lucro. A flexibilização das normas urbanísticas apresenta um caráter elitista por promover a expulsão da população pobre das áreas de interesse, principalmente para 0 mercado imobiliário.

$\mathrm{Na}$ tentativa de reverter a decisão de remoção, os moradores procuraram o apoio de grupos oriundos de universidades públicas e elaboraram um plano de urbanização, o Plano Popular da Vila Autódromo ${ }^{6}$, propondo, como alternativa à remoção, a urbanização da favela, que teria um custo mais reduzido se comparado à remoção e reassentamento dos moradores, proposto pela prefeitura. 0 prefeito se reuniu com alguns moradores e prometeu analisar o plano elaborado para a Vila Autódromo e divulgar uma posição. No entanto, os moradores jamais obtiveram um retorno sobre essa proposta. 0 processo de remoção deu início sem que os moradores participassem dos espaços de decisão e sem que fossem consideradas suas propostas, caracterizando uma ação autoritária da prefeitura.

Para entendermos como se deu o processo de remoção, entrevistamos alguns moradores que descreveram as ações realizadas pela prefeitura. Segundo os moradores, eles souberam que seriam removidos através de diversas mídias: televisão, jornal, redes sociais, entre outras. 0 primeiro contato que tiveram com representantes da prefeitura foi através de equipes, que passavam nas casas para realizar 0 cadastramento das famílias e a medição das casas. Estas equipes apresentavam um discurso coercitivo de que todos iriam ser removidos.

Muitos moradores se recusaram a realizar o cadastro, justificando que tinham o direito de permanecer e se mobilizaram para convencer outros moradores a resistir. Juntamente com diversos grupos de apoio (acadêmicos, militantes, políticos), a Vila Autódromo criou uma forte resistência contra a remoção.

De acordo com os relatos dos moradores, uma das estratégias da prefeitura para desarticular o movimento de resistência foi a negociação individual com os moradores e a cooptação de alguns para convencer aos demais a negociarem com a prefeitura. No início, com o movimento de resistência não consolidado, as famílias removidas não tiveram um poder de negociação maior com a 
prefeitura, optando por receber indenização em dinheiro ou receber um apartamento em um conjunto habitacional erguido pela prefeitura. Com a intensificação do movimento de resistência e a diminuição de prazos para a realização dos Jogos Olímpicos, a prefeitura começou a realizar negociações mais vantajosas, com indenizações com valores mais altos e algumas famílias chegaram a receber indenizações e apartamentos. Soubemos de casos de famílias que receberam mais de um apartamento, onde cada imóvel era registrado em nome de diferentes membros da família.

Com a finalidade de receber os moradores removidos da Vila Autódromo, a prefeitura construiu um conjunto habitacional com 900 apartamentos distribuídos em 4 condomínios, chamado de Parque Carioca ${ }^{7}$, situado a 1,5 km da Vila Autódromo. Seus principais atrativos eram as áreas de lazer à imagem de condomínios de classe média da região. Atualmente, já existem diversas queixas sobre a qualidade dessas construções ${ }^{8}$.

Azevedo e Faulhaber (2015) constataram que a maioria das pessoas oriundas das favelas removidas era reassentada em locais distantes da sua moradia anterior, principalmente na zona oeste da cidade, área distante do centro da cidade e da zona sul, caracterizando a remoção como um instrumento de segregação espacial. Diferentemente desses casos, as famílias removidas da Vila Autódromo foram destinadas a um conjunto habitacional próximo à localidade. Isso foi certamente resultado do árduo movimento de resistência engendrado pelos moradores e seus apoiadores.

Além da negociação de forma individualizada, a prefeitura utilizou-se de pressão psicológica, através de inúmeras ligações telefônicas para que os moradores aceitassem sair de suas casas. À medida que as famílias saíam de suas casas, a prefeitura realizava imediatamente a demolição das moradias e não retirava os escombros, na tentativa de inviabilizar a permanência dos demais moradores que estavam resistindo à remoção. A estratégia da prefeitura era criar o caos, inviabilizando a vida na favela. O local, outrora consolidado, foi paulatinamente destruído pela prefeitura, que deixava os escombros e não providenciava mais nenhum reparo nos serviços, tais como água e luz. Através de determinação judicial, movida pelo Núcleo de Terras e Habitação da Defensoria Pública do Rio de Janeiro, a prefeitura foi obrigada ao menos a retirar o entulho; caso contrário, seria multada.

Os moradores perceberam que à medida que as casas iriam sendo medidas e cadastradas, as famílias começavam a receber propostas de negociação, pessoalmente ou por telefone, sendo bastante assediados para fazer a negociação com a prefeitura. As casas que não eram medidas foram permanecendo. Estrategicamente, muitos moradores se recusaram a fazer o cadastro $\mathrm{e}$ não permitiram que os funcionários entrassem nas suas casas. Muitas casas foram marcadas somente após decisão judicial de ação movida pela prefeitura. 
Através do decreto de desapropriação $n^{0} 39.852$ de 18 de março de 2015, a prefeitura definiu as casas que deveriam ser demolidas, deixando os moradores que ainda resistiam receosos. Ao descobrirem que suas casas constavam nesse decreto, muitos moradores saíram do movimento de resistência por medo de não conseguirem uma indenização satisfatória e negociaram diretamente com a prefeitura, já que a avaliação realizada por medida judicial era inferior à que a prefeitura oferecia. Nesse momento, já poucas famílias persistiam na resistência.

Além dos moradores, entrevistamos, também, assistentes sociais que, de alguma forma, estiveram envolvidas com o processo de remoção, especialmente da Vila Autódromo. Através dessas entrevistas, constatamos que a prefeitura orientava os diversos profissionais a ter uma postura persuasiva com os moradores, de forma a convencê-los de sair da localidade. "A gente tinha que conversar, fazer um trabalho de convencimento para os moradores deixarem a Vila Autódromo. [...] As assistentes sociais entravam na casa que seria removida, faziam o cadastro e o técnico de edificação tirava as medidas e fotos da moradia." (Informação verbal) ${ }^{9}$.

Havia metas diárias de cadastramentos que precisavam ser realizados. Por outro lado, as informações prestadas pela prefeitura aos moradores nunca eram claras e, por vezes, contraditórias. A falta de informação apresentava ser uma estratégia de ação, o que dificultava as formas de mobilização política. Um dos moradores nos relatou que muitos não aguentaram o processo de remoção:

\begin{abstract}
Nem todos suportam esse movimento de remoção. Muita gente passou mal, idosos passaram mal. A prefeitura é muito perversa. Nos deixaram num cenário de guerra, uma pressão psicológica e com violência física. Ligações constantes para os moradores. Depois que a casa era medida, recebia ligações direto. Tinha morador que recebia 15 ligações por dia. Um assédio! Batiam na sua porta, ligavam... Depois que mediam a casa, virava 0 inferno. Diziam que mesmo medindo ninguém seria obrigado a sair. 0 medir já era uma estratégia. Começava as ligações, as brigas familiares, muitas famílias se fragmentaram, casais se separam, algumas famílias para não se separarem, alguém tinha que ceder, e geralmente quem cedia era para sair. (Informação verbal) ${ }^{10}$.
\end{abstract}

O processo se realizou de forma truculenta, com a participação da Guarda Municipal, principalmente nos casos de despejos. Foram diversos os casos de conflito entre a Guarda e os moradores, resultando, muitas vezes, na agressão física contra esses.

Por causa do movimento de resistência, a Vila Autódromo ganhou apoio de grupos da sociedade civil, de universidades, da mídia alternativa e mesmo de entidades e grupos internacionais. Segundo os próprios moradores, pessoas que também passaram pelo processo de remoção em seus países, por conta da realização de megaeventos esportivos, enviaram mensagens de apoio. Foi graças ao movimento de resistência que a Vila Autódromo continuou existindo. Às 20 últimas famílias que permaneceram no local, a prefeitura elaborou um plano de urbanização que previa a construção de casas geminadas, uma para cada família, além de escola, área de lazer, esgoto, iluminação, 
pavimentação, paisagismo e calçadas. Os moradores reclamam que esse projeto foi elaborado sem os consultar e divulgado primeiramente para a imprensa, ao invés deles, os principais interessados. Após reivindicações, os moradores se reuniram com o prefeito e reivindicaram por mudanças no projeto, como a construção de um quintal ao redor da casa, ao contrário das casas geminadas propostas pela prefeitura, um detalhe, que, para eles, era considerado muito importante. Isso demonstra que a luta e a organização dos moradores foram importantes do início ao fim do processo de remoção.

As casas foram construídas e entregues no mês de julho de 2016, mês anterior ao início dos Jogos Olímpicos. Apesar de permanecerem no local, esses moradores nos relataram que o processo de remoção afetou também as relações sociais entre familiares e entre vizinhos. Muitas famílias se fragmentaram, porque seus membros não tinham um consenso entre resistir ou aceitar a oferta da prefeitura. Um dos moradores entrevistados nos relatou que perdeu o vínculo com parentes e antigos vizinhos por continuar resistindo à remoção. (Figura 1).

\section{Figura 1 - Projeto proposto pela Prefeitura do Rio de Janeiro}

\section{PROJETO DE URBANIZAÇÃO VILA AUTÓDROMO}

\section{- CASAS DE DOIS QUARTOS COM QUINTAL \\ - PAVIMENTAÇÃo E CALÇADAS \\ - DRENAGEM \\ - ESGOTO \\ - ILUMINAÇÃo \\ - PAISAGISMO \\ - escolas \\ - ÁREAs DE LAZER}

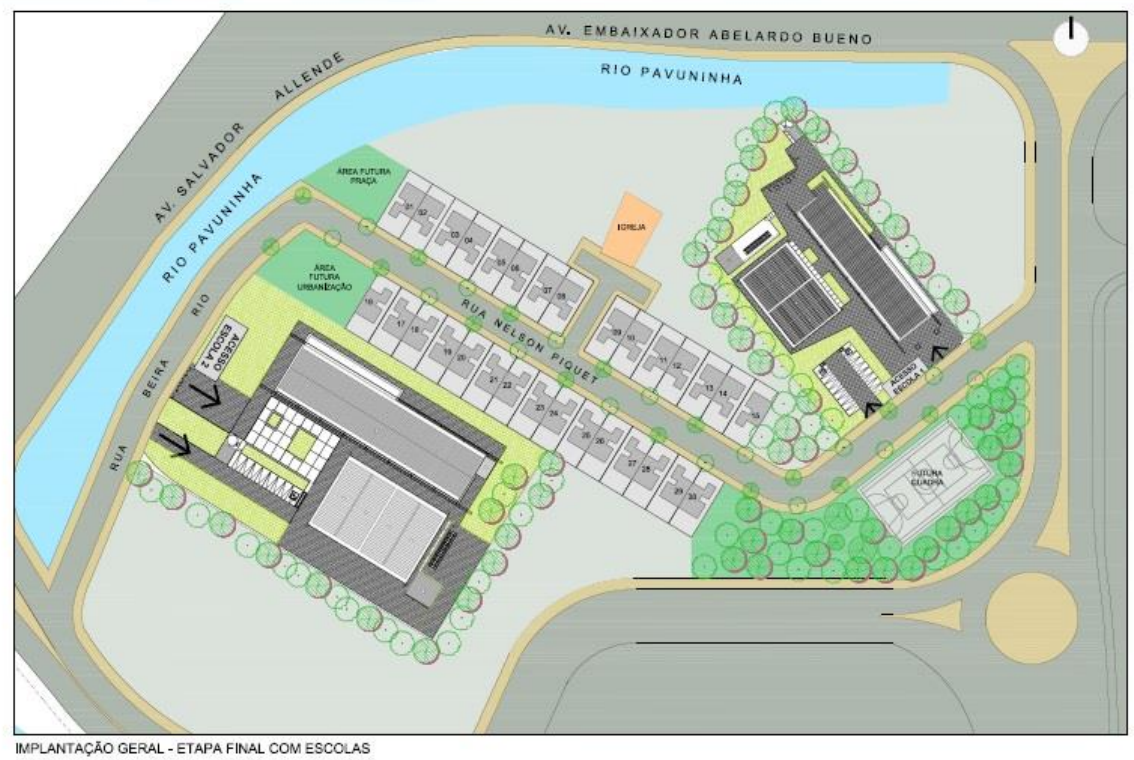

Fonte: RIO DE JANEIRO. Urbanização da Vila Autódromo. Rio de Janeiro, 2016. Disponível em: https://riorealblog.files.wordpress.com/2016/03/vila-autodromo2.pdf . Acesso em: 3 ago. 2017.

A única estrutura que resistiu às remoções foi a capela local. É importante salientar que essa capela foi um local importante de resistência, tanto pelo apoio de alguns padres católicos à causa quanto à disponibilidade dos espaços para acolher reuniões e mesmo os arquivos da associação de moradores após a destruição da sua sede. Uma das reivindicações dos moradores foi a construção de um espaço destinado ao Museu das Remoções. Segundo folheto bilíngue distribuído por eles (Figura 2): 
O Museu nasceu da articulação entre os moradores da Vila Autódromo e seus apoiadores. Seu objetivo é registrar a história de violências, mas também de lutas, que ocorreram nos últimos anos. Tal experiência surge da necessidade de enfrentar o duplo processo de apagamento buscado pelas práticas estatais: tanto do espaço físico quanto das redes de relações (afetivas, morais, políticas e econômicas) que formaram historicamente a comunidade. Este Museu é mais um ato de resistência da Vila Autódromo. Memória não se remove! (Informação verbal, grifos do autor). ${ }^{11}$

\section{Figura 2 - Folheto distribuído pelos moradores da Vila Autódromo em visita realizada em agosto de 2016}

Fonte: Acervo pessoal do autores.
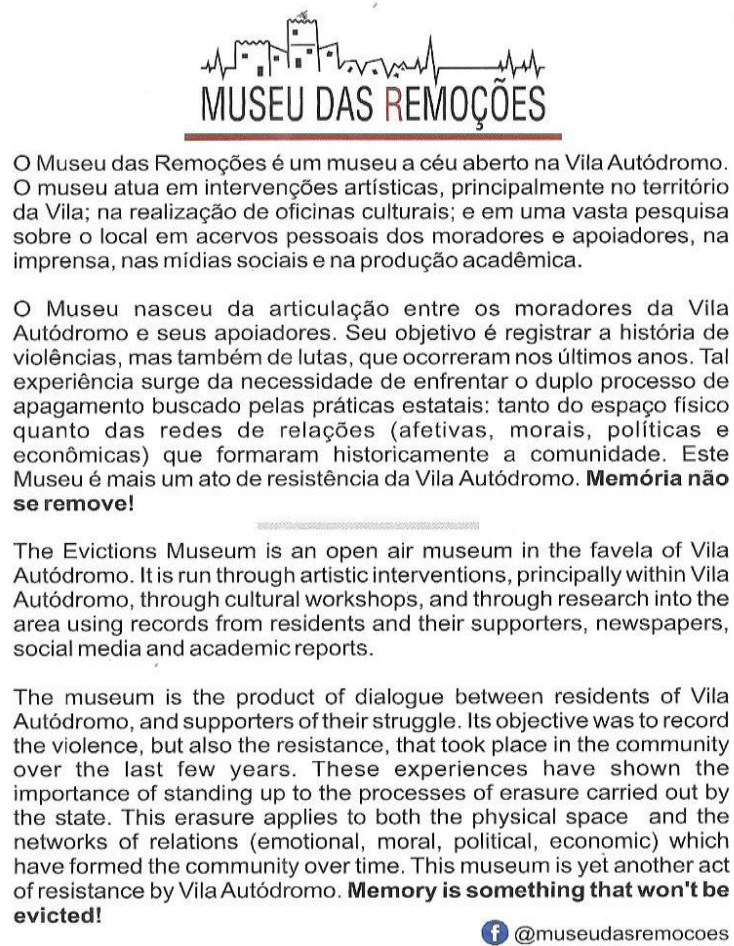

O Museu das Remoções é um museu a céu aberto na Vila Autódromo. O museu atua em intervencões artísticas, principalmente no território da Vila; na realizaçăo de oficinas culturais; e em uma vasta pesquisa sobre o local em acervos pessoais dos moradores e apoiadores, na imprensa, nas midias sociais e na produção acadêmica.

O Museu nasceu da articulação entre os moradores da Vila Autódromo e seus apoiadores. Seu objetivo é registrar a história de experiênci sur de ne apagamento buscado pelas práticas estatais: tanto do espaco físico quanto das redes de relaçöes (afetivas, morais, políticas e econômicas) que formaram historicamente a comunidade. Este seremovel

The Evictions Museum is an open air museum in the favela of Vila Autódromo. It is run through artistic interventions, principally within Vila Autódromo, through cultural workshops, and through research into the area using records from residents and their supporters, newspapers, social media and academic reports. the violence, but also the resistance, that took place in the community last few years. These experien the state. This erasure applies to both the physical space and the networks of relations (emotional, moral, political, economic) which of resistance by Vila Autódromo. Memory is something that won"t be evicted!

$$
\text { (1)@museudasremocoes }
$$

O intuito do Museu das Remoções é levantar trabalhos acadêmicos, reportagens e outros materiais que contam de alguma forma a história da Vila Autódromo, principalmente durante 0 processo de remoção. Durante as remoções, os moradores organizaram muitos debates e eventos culturais, que permanecem acontecendo até os dias de hoje. O Museu das Remoções se insere, assim, no esforço de vários movimentos de favelas de criarem museus sociais, fazendo da memória uma ferramenta política. (GONÇALVES; LESSA, 2018).

Trata-se de uma experiência de museologia social, que não serve apenas à preservação de coisas, objetos e artefatos, mas, sobretudo, à valorização da vida, como "[...] vivência e convivência, como potência não orgânica de vida, como potência de criação e de resistência." (CHAGAS; BOGADO, 2017, p. 141). A museologia social está comprometida com a redução das injustiças e desigualdades 
sociais e com a utilização do poder da memória, do patrimônio e do museu a favor dos grupos populares. (CHAGAS; GOUVEA, 2014).

Apesar da destruição quase completa da Vila Autódromo, a ideia é manter viva a memória desse local e as lutas de seus moradores pela consolidação de uma cidade mais justa e includente.

\section{CONCLUSÃO}

O Rio de Janeiro se encontra em uma situação bem diferente da que foi anunciada por autoridades e empresários com a realização dos Jogos Olímpicos. Ao contrário dos discursos de desenvolvimento econômico e social, a cidade se encontra em uma grave crise econômica, com o aumento do desemprego, dos índices de violência e da sensação de abandono da cidade pelo poder público, o que foi reforçado pela gestão caótica e proselitista do atual prefeito Marcelo Crivella. Não podemos atribuir toda a crise à realização desses megaeventos, mas podemos afirmar que o ciclo de preparação da cidade contribuiu para seu agravamento, uma vez que, vultosos investimentos públicos foram destinados para sua realização.

Esses investimentos foram guiados de acordo com a lógica de mercado em detrimento das reais necessidades da maioria da população carioca. As intervenções urbanas privilegiaram áreas com grande potencial de valorização, importantes, principalmente, para o mercado imobiliário. 0 que se pretendeu foi criar as condições ideais de acumulação, que beneficiou determinados setores do mercado, A cidade foi pensada como empresa e mercadoria, orientada pelo e para o mercado. (VAINER, 2000).

Uma das grandes marcas das intervenções urbanas nesse contexto foi a remoção de inúmeras favelas do cenário urbano carioca, com a transferência dos moradores para áreas distantes da cidade. Isso permitiu a liberação de terras ora ocupadas por essas favelas, contribuindo também para uma maior valorização das áreas adjacentes. A remoção da Vila Autódromo foi certamente o caso modelo de uma forma de planejamento urbano elitista e segregador do fracassado projeto olímpico da cidade do Rio de Janeiro.

\section{REFERÊNCIAS}

ASSOCIAÇÃO DE MORADORES E PESCADORES DA VILA AUTÓDROMO. Plano Popular da Vila Autódromo: plano de desenvolvimento urbano, econômico, social e cultural. Rio de Janeiro, 2012. Disponível em: https://comitepopulario.files.wordpress.com/2012/08/planopopularvilaautodromo.pdf. Acesso em: 15 jun. 2017

AZEVEDO, L.; FAULHABER.L. SMH 2016: remoções no Rio de Janeiro olímpico. Rio de Janeiro: Mórula, 2015. 
BRUM. M. Favelas e remocionismo ontem e hoje: da ditadura de 1964 aos grandes eventos. 0 Social em Questão, Rio de Janeiro, ano XVI, n. 29, p. 179-208, 2013.

CHAGAS, M.; GOUVEIA, I. Museologia social: reflexões e práticas (à guisa de apresentação),

Cadernos do CEOM, Passo dos Fortes Chapecó, n. 41, p. 9-21, 2014.

CHAGAS. M.; BOGADO, D. A museologia que não serve para a vida, não serve para nada: o museu das remoções como potência criativa e potência de resistência. In CALABRE, L. et al. (org.). Memória das olimpíadas no Brasil: diálogos e olhares. Rio de Janeiro: Fundação Casa de Rui Barbosa, 2017. p.139-146.

DEBORD, G. La Sociètè du Spectacle. París: Champ Libre, 1967.

DELGADO, M. La ciudad mentirosa, fraude y miseria del "modelo Barcelona". Madrid: Catarata, 2007.

FRANÇA, V. R. Temas diversos sobre a concessão de direito real do uso celebrada por sociedade de economia mista. Revista de Informação Legislativa, Brasília, DF, v. 43, n. 171, p. 225-232, 2006.

GAFFNEY, C. Forjando os anéis: a paisagem imobiliária pré-olímpica no Rio de janeiro. E-Metrópolis. Rio de Janeiro, ano 4, n.15, p. 7-20, 2013.

GONÇALVES, R. S. O espetáculo da paisagem carioca, novas configurações urbanas e seus espaços sociais. In GOMES, M. F. C. M. et al. (orgs.). Renovação urbana, mercantilização da cidade e desigualdades socioespaciais. Rio de Janeiro: Mauad X, 2013.

GONÇALVES, R. S.; FRANÇA, B. A. Entre o muro e a remoção: meio ambiente e favelas no Rio de Janeiro. In GOMES, M. F. C. M.; BARBOSA, M. J. S. B. (orgs). Cidade e sustentabilidade:

mecanismos de controle e resistência. Rio de Janeiro: Terra Vermelha, 2010.

GONÇALVES, R. S.; LESSA, V.M., A luta pelo direito à cidade: o uso dos recursos digitais pelos moradores do Horto Florestal do Rio de Janeiro contra a remoção do seu bairro. In MENEZES, M.

Neighbourhood \& City - Between digital and analogue perspectives. Lisboa: Edições Universitárias Lusófona, 2018. p. 20-28. (CyberParks Project. Series Culture and Territory, n. 3).

GONÇALVES, R.S. Do Centenário à Olimpíada: megaeventos e seus impactos sociais na cidade do Rio de Janeiro em uma perspectiva histórica. Revista Praia Vermelha, Rio de Janeiro, v. 24, n. 1, p. 17-41, 2014.

GUIMARÃES, R. C. V. Barra da Tijuca e o Projeto Olímpico: a cidade do capital. 2015. Dissertação (Mestrado em Planejamento Urbano e Regional) - Instituto de Pesquisa e Planejamento Urbano e Regional, Universidade Federal do Rio de Janeiro, Rio de Janeiro, 2015.

LUSSAULT, M. L'homme spatial : La construction sociale de l'espace humain. Paris: Editions du Seuil, 2007.

RIO DE JANEIRO. Plano Diretor. Lei Complementar n. 111 de $1^{\circ}$ de fevereiro de 2011. Dispõe sobre a política Urbana e Ambiental do Município, institui o Plano Diretor de Desenvolvimento Urbano Sustentável do Município do Rio de Janeiro e dá outras providências. Rio de Janeiro, 2011. Disponível 
em : http://www.rio.rj.gov.br/dlstatic/10112/139339/DLFE-

229591.pdf/LeiComplementar1112011PlanoDiretor.pdf. Acesso em: 18 jul. 2018.

RIO DE JANEIRO. Urbanização da Vila Autódromo. Rio de Janeiro, 2016. Disponível em: https://riorealblog.files.wordpress.com/2016/03/vila-autodromo2.pdf . Acesso em: 3 ago. 2017.

SANCHEZ, F. A (in) sustentabilidade das cidades-vitrine. In ACSERALD, H. A duração das cidades: sustentabilidade e risco nas políticas urbanas. Rio de Janeiro: Lamparina, 2009. p. 171-192.

SMITH, N. A gentrificação generalizada: de uma anomalia local à "regeneração" urbana como estratégia urbana global. In BIDOUZACHARIASEN, B. De volta à cidade: dos processos de gentrificação às políticas de "revitalização" dos centros urbanos, São Paulo: Annablume, 2006. p. 5987.

VAINER. C. B. Pátria, empresa e mercadoria: notas sobre a estratégia discursiva do Planejamento Estratégico Urbano. In ARANTES, O.; VAINER, C. B.; MARICATO, E. (orgs.). A cidade do pensamento único: desmanchando consensos. Petropólis, RJ: Vozes, 2000. p. 75-103.

\section{Notas}

1 Texto elaborado a partir de pesquisa realizada para a dissertação de mestrado da primeira autora sob orientação do segundo autor, que contou com recursos, em forma de bolsa, do Conselho Nacional de Pesquisa (CNPq).

2 O GTAPM, Grupo de Trabalho Acadêmico Profissional Multidisciplinar, foi constituído por integrantes de diversas instituições de diversas áreas com o intuito de elaborar um laudo técnico sobre as verdadeiras condições da Vila Autódromo, confrontando os projetos da prefeitura e dos moradores (Disponível em: http://lemetro.ifcs.ufrj.br/gtapm_parecer_2013.pdf. Acesso em: 15 jun. 2017).

3 "Mediante a concessão de direito real de uso, a administração pública pode ceder o uso de bens de seu domínio para 0 particular, de forma remunerada ou gratuita, por tempo certo ou indeterminado, sob a forma de direito real resolúvel, para o desenvolvimento e implementação de atividades socioeconômicas que sejam relevantes para o interesse público." (FRANÇA, 2006, p. 1).

4 "Área de Especial Interesse Social - AEIS é aquela destinada a Programas Habitacionais de Interesse Social - HIS, destinados prioritariamente a famílias de renda igual ou inferior a seis salários mínimos, de promoção pública ou a ela vinculada, admitindo-se usos de caráter local complementares ao residencial, tais como comércio, equipamentos comunitários de educação e saúde e áreas de esporte e lazer" (RIO DE JANEIRO, 2011).

5 Sobre o Campo de Golfe, ler Dossiê sobre as violações do direito ao esporte e à cidade (Disponível em: http://www.observatoriodasmetropoles.net/images/abook_file/dossie_violacoesesporte_rio2015.pdf. Acesso em: 15 jun. 2017). Sobre a construção da Transolímpica, ler matéria divulgada pelo site UOL (Disponível em: https://esporte.uol.com.br/rio-2016/ultimas-noticias/2014/04/15/obra-de-avenida-olimpica-do-rio-vai-derrubar-200-mil-mde-mata-atlantica.htm. Acesso em: 15 jun. 2017).

6 O Plano Popular da Vila Autódromo foi elaborado pelos moradores da Vila Autódromo com o apoio do Instituto de Pesquisa e Planejamento Urbano Regional da Universidade Federal do Rio de Janeiro (IPPUR/UFRJ) e do Núcleo de Estudos e Projetos Habitacionais e Urbanos da Universidade Federal Fluminense (NEPHU/UFF). (Associação de Moradores e Pescadores da Vila Autódromo, 2012).

7 Projeto (Disponível em: http://www.rio.rj.gov.br/dlstatic/10112/3641881/DLFE267980.pdf/Apresentacao_Parque_Carioca_2.0.1.3..pdf. Acesso em: 15 jun. 2017).

8 Denúncias publicadas no site (Disponível em: http://rioonwatch.org.br/?p=20108. Acesso em: 15 jun. 2017).

9 Depoimento retirado da entrevista realizada em dezembro de 2016 com a Assistente Social que trabalhou no processo de remoção de algumas favelas, inclusive da Vila Autódromo. 
REMOÇÕES E MEGAEVENTOS NO RIO DE JANEIRO: a luta de resistência dos moradores da Vila Autódromo

10 Depoimento retirado da entrevista realizada em agosto de 2016 com Morador 1.

${ }^{11}$ Folheto distribuído pelos moradores da Vila Autódromo em visita realizada no mês de agosto de 2016. 